\title{
CED-4 forms a $2: 2$ heterotetrameric complex with CED-9 until specifically displaced by EGL-1 or CED-13
}

\author{
WD Fairlie, ${ }^{*, 1}$ MA Perugini ${ }^{2,3}$, M Kvansakul', L Chen ${ }^{1}$, \\ DCS Huang ${ }^{1}$ and PM Colman ${ }^{1}$ \\ 1 The Walter and Eliza Hall Institute of Medical Research, Parkville, Victoria, \\ Australia \\ 2 Russell Grimwade School of Biochemistry and Molecular Biology, University of \\ Melbourne, Parkville, Victoria, Australia \\ 3 Bio21 Molecular Science and Biotechnology Institute, University of Melbourne, \\ Parkville, Victoria, Australia \\ * Corresponding author: WD Fairlie, Structural Biology Division, The Walter and \\ Eliza Hall Institute of Medical Research, $1 G$ Royal Parade, Parkville, Victoria \\ 3050, Australia. Tel: + 6139345 2309; Fax: + 6139345 2686; \\ E-mail: fairlie@wehi.edu.au
}

Received 22.3.05; revised 29.7.05; accepted 03.8.05; published online 16.9.05 Edited by M Hengartner

\begin{abstract}
The pathway to cell death in Caenorhabditis elegans is well established. In cells undergoing apoptosis, the Bcl-2 homology domain 3 (BH3)-only protein EGL-1 binds to CED-9 at the mitochondrial membrane to cause the release of CED-4, which oligomerises and facilitates the activation of the caspase CED-3. However, despite many studies, the biophysical features of the CED-4/CED-9 complex have not been fully characterised. Here, we report the purification of a soluble and stable 2:2 heterotetrameric complex formed by recombinant CED-4 and CED-9 coexpressed in bacteria. Consistent with previous studies, synthetic peptides corresponding to the $\mathrm{BH} 3$ domains of worm BH3-only proteins (EGL-1, CED-13) dissociate CED-4 from CED-9, but not from the gain-offunction CED-9 (G169E) mutant. Surprisingly, the ability of worm BH3 domains to dissociate CED-4 was specific since mammalian BH3-only proteins could not do so.

Cell Death and Differentiation (2006) 13, 426-434.

doi:10.1038/sj.cdd.4401762; published online 16 September 2005
\end{abstract}

Keywords: apoptosis; Caenorhabditis elegans; CED-4; CED-9; EGL-1; Bcl-2; APAF-1

Abbreviations: $\mathrm{Bcl}-2$, B-cell lymphoma-2; $\mathrm{BH} 3, \mathrm{Bcl}-2$ homology domain 3; CARD, caspase recruitment domain; NB-ARC, nucleotide-binding domain shared by APAF-1, certain $R$ gene products and CED-4; ITC, isothermal titration calorimetry; APAF-1, apoptotic protease-activating factor 1

\section{Introduction}

Much of our current understanding of the pathways to programmed cell death has been learned from genetic analysis of the nematode Caenorhabitditis elegans. ${ }^{1}$ In this organism, three genes essential for the execution of apoptosis have been identified, namely ced-3, ced $-4,{ }^{2}$ and egl- $1,{ }^{3}$ whereas another, ced-9, antagonizes cell death. ${ }^{4}$ In healthy cells, the adapter CED-4 associates with CED-9, the worm B-cell lymphoma-2 (Bcl-2) orthologue, on mitochondrial membranes. ${ }^{5}$ When the cell receives a death signal, transcriptionally upregulated $\mathrm{Bcl}-2$ homology domain 3 (BH3)-only protein EGL-1 binds CED-9. This, in turn, releases CED-4 allowing its oligomerisation and leads to the activation of the caspase CED-3 which is synthesised as an inactive zymogen. ${ }^{6}$ CED-4 facilitates proteolytic autoactivation of CED-3 by bringing CED-3 zymogens into close proximity through interactions between their caspase-recruitment domains (CARDs) (Figure 1). However, it is not known whether the CED-4/CED-9 complex at the mitochondrial membrane contains CED- 3 constitutively, although during cell death, CED-4 dissociates from CED-9 and translocates from the mitochondrial to the nuclear membrane. ${ }^{5}$

This pathway of protein interactions has been extensively studied using a myriad of techniques. For example, interaction of CED-4 with CED-9 (and simultaneously with CED-3) has been demonstrated by co-immunoprecipitation of proteins expressed in various cell types, ${ }^{6-8}$ the yeast two-hybrid system, ${ }^{9-11}$ or by colocalization studies. ${ }^{5,12,13}$ These have been complemented by mutational analysis of both CED-4 and CED-9. ${ }^{9,10,14}$ Similarly, numerous studies have demonstrated the interaction between CED-9 and EGL-1, and release and/or redistribution of CED-4 from the mitochondria. $^{3,12,14-16}$

Recently, three-dimensional structures were determined for the $\mathrm{Bcl}-2$ homology region of CED-9 alone ${ }^{16}$ and in complex with an EGL-1 fragment encompassing its $\mathrm{BH} 3$ domain, ${ }^{14}$ confirming the structural similarity with the mammalian $\mathrm{Bcl}-2$ prosurvival family members ${ }^{17,18}$ and their mode of engagement with $\mathrm{BH} 3$ domains. ${ }^{19-21}$ These structures of CED-9 suggest a mechanism by which CED-4 is released from CED-9. Binding of EGL-1 through its $\mathrm{BH} 3$ domain to a hydrophobic cleft in CED-9 results in a substantial structural rearrangement in CED-9, which is proposed to disrupt binding to CED-4 at a second site on CED-9. ${ }^{14}$ The CED-9/EGL-1 complex structure also explained a ced-9 gain-of-function mutation that prevents most somatic cell deaths in $C$. elegans. ${ }^{22}$ This mutation substitutes the highly conserved glycine residue at position 169 with glutamic acid and prevents EGL-1-induced release of CED-4, but preserves CED-4 binding to CED-9. , $^{5,15}$ The CED-9/EGL-1 complex structure shows that the replacement of glycine with glutamic acid would introduce a steric clash with EGL-1, thereby negatively affecting its binding. ${ }^{14}$

The three-dimensional structure of the mammalian homologue of CED-4, apoptotic protease-activating factor 1 (APAF-1), with WD40 domains deleted, has also recently been solved. ${ }^{23}$ This structure showed a relatively compact protein of five distinct domains with the amino terminal CARD at one end and the C-terminus at the other (Figure 1). An ADP molecule was found deeply buried within the protein at the junction of four domains and appears to serve as an organising centre to 


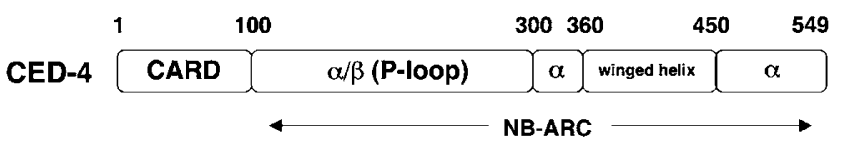

CED-9 $\underbrace{1}_{- \text {N-term. }} \begin{aligned} & 68 \\ & \text { BCl-2 homology }\end{aligned}$

Figure 1 Domain architecture of CED-4 and CED-9. CED-4 consists of an Nterminal caspase recruitment domain (CARD) required for binding CED-3 and a C-terminal nucleotide-binding domain shared by APAF-1, certain plant $R$ gene products and CED-4 (NB-ARC). The subdomain structure shown is taken from the APAF-1 structure. ${ }^{23}$ CED-9 has an N-terminal domain, a central domain homologous to mammalian Bcl-2 prosurvival proteins, and a C-terminal hydrophobic transmembrane segment that was deleted in all constructs used

lock the molecule into an inactive state. Owing to the packing of the CED-4 CARD in this structure, a conformational change, presumably as a consequence of ATP hydrolysis, is required for interaction with the caspase- 9 prodomain.

Most of the above functional studies on the CED-3/CED-4/ CED-9 interaction and its modulation by EGL-1 have been done in cell-based assays, and have thus not addressed relevant biophysical questions regarding these macromolecular complexes, although some attempts at characterising recombinant proteins have been reported. For example, it has been shown that recombinant CED-4 produced in insect cells spontaneously oligomerises, ${ }^{24}$ a result consistent with studies indicating that CED-9 prevents CED-4 oligomerisation. ${ }^{6} \mathrm{Gel}-$ filtration chromatography estimates of the mass of the CED-4 oligomers produced from the various constructs used in this study ranged from 500 to $1500 \mathrm{kDa}$. However, no studies to date have addressed the question of the size and stoichiometry of the CED-9/CED-4 complex. In this paper we report, for the first time, high-level expression of recombinant CED-4/ CED-9 complex in bacteria. This purified protein complex is a $2: 2$ heterotetramer and responds predictably to treatment with EGL-1. Furthermore, we demonstrate that the trigger required for release of CED-9 from CED-4 is highly specific since it can only be initiated by worm, but not mammalian, BH3-only proteins.

\section{Results}

\section{Expression and purification of CED-4/CED-9 complex}

To study the biochemical properties of the adapter molecule CED-4, we initially attempted to express either the full-length protein or its predicted domains in Escherichia coli. These fragments included the N-terminal CARD, the nucleotidebinding domain shared by APAF-1, certain $\underline{R}$ gene products and CED-4 (NB-ARC) or a shorter form of the NB-ARC that just encompassed the P-loop ATP-binding domain (Figure 1). In all cases, relatively high levels of protein were expressed (mg/l of culture) but their poor solubility precluded us from purifying and characterising them in detail.

To circumvent this problem, we attempted coexpressing CED-4 with its physiological binding partner, CED- $9,{ }^{9}$ using a dual expression vector. Although most of the CED-4

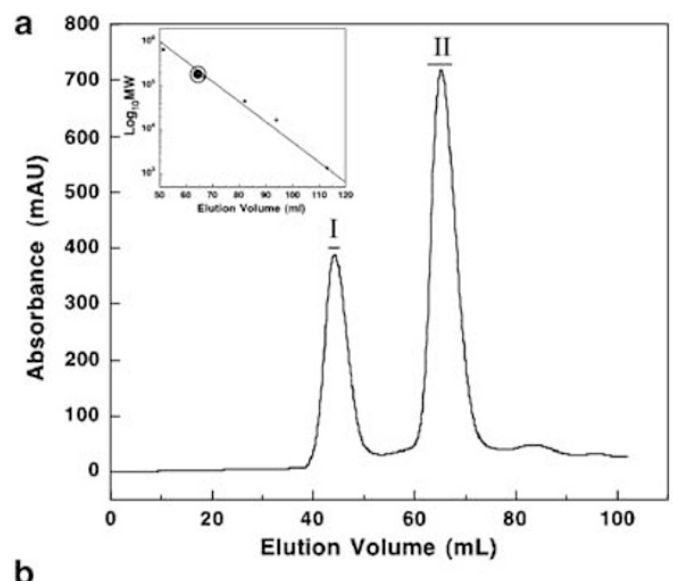

b

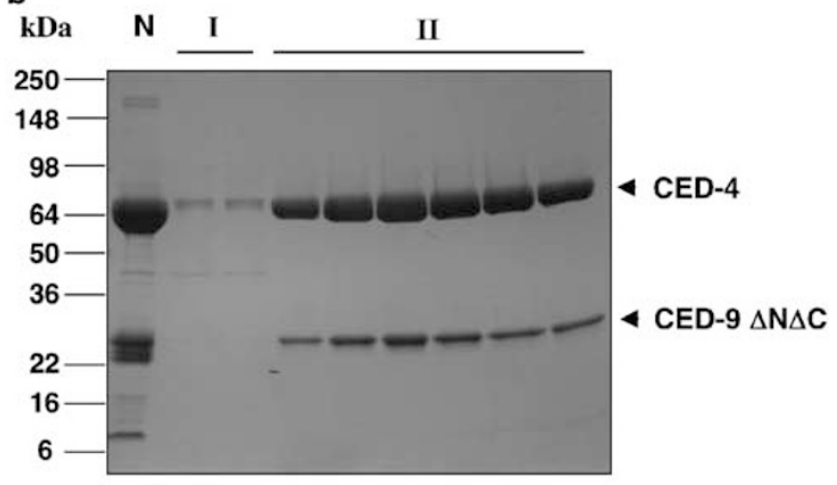

C
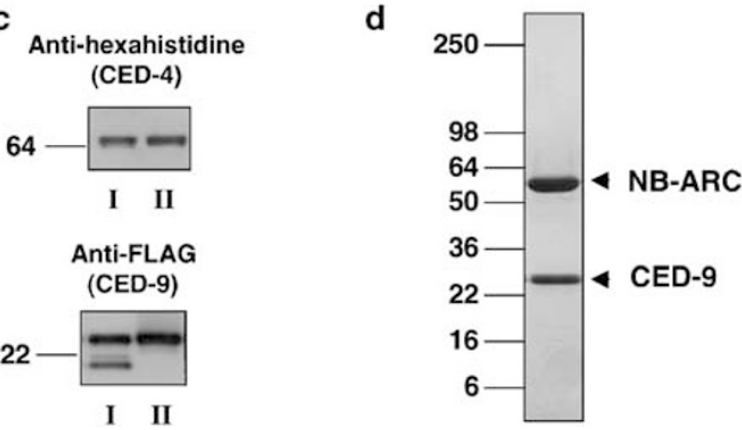

Figure 2 Purification of CED-4/CED-9 complex. (a) Gel-filtration profile of CED-4/CED-9 complex following Nickel-affinity chromatography. The inset shows a standard curve based on the retention time of molecular weight standards. The circled point indicates the apparent molecular weight/retention time of the protein complex in Peak II. (b) Coomassie Blue-stained gel of the eluate from Nickel-affinity chromatography $(\mathrm{N})$, or fractions from Peak I and II of CED-4/CED-9 complex purified as indicated in (a). (c) Western blot analysis of the central fractions from Peaks I or II isolated in (a). Hexahistidine-tagged CED-4 and FLAG-tagged CED-9 are present in both peaks. (d) Coomasie Blue-stained gel of the main fraction of purified CED-4 NB-ARC/CED-9 complex

expressed using this system remained insoluble, there was sufficient soluble material to allow purification of a complex of CED-4 with CED-9. Encouragingly, 1-10 mg (per litre of bacterial culture) of the protein complex was isolated from the soluble fraction of bacterial lysates using a two-step purification protocol involving an initial Nickel-affinity purification step (employing the hexahistidine tag on the N-terminus of CED-4) followed by a gel-filtration chromatography step (Figure 2a-c). Typically, the gel-filtration chromatogram 
of protein complexes recovered from the Nickel-affinity purification indicated that, in some preparations, up to onethird of the purified material was a soluble high molecular weight aggregate, which eluted near the column void volume (Figure 2a, Peak I). Western blot analysis of this peak showed that it, like the major peak (Figure 2a, Peak II), contained both CED-4 and CED-9, although unlike the major peak it includes a putative CED-9 degradation product (Figure 2c). The Peak I complex also displayed a relatively high absorbance at $340 \mathrm{~nm}$, suggesting that it may be a soluble protein aggregate. Therefore, subsequent studies used only the major fraction eluted in Peak II (Figure 2a).

We tested two different CED-9 constructs in the coexpression studies: one lacking its $\mathrm{C}$-terminal hydrophobic tail (CED$9 \Delta C$ ) and another in which both the hydrophobic tail and the amino-terminal 67 residues were removed (CED-9 $\Delta \mathrm{N} \Delta \mathrm{C}$ ) (Figure 1). The gel-filtration profiles of the complex containing either of these CED-9 constructs were very similar (data not shown). As the CED-9 $\Delta \mathrm{N} \Delta \mathrm{C}$ protein expressed alone was generally more soluble, and thus more readily amenable for further characterisation, we focused our efforts on complexes formed between this protein and CED-4. In fact, purified CED4/CED-9 $\Delta \mathrm{N} \Delta \mathrm{C}$ complex could be concentrated to reasonably high levels ( $>30 \mathrm{mg} / \mathrm{ml}$ ) without further aggregation apparent, as judged by re-chromatography on a size-exclusion column. This complex was also stable after up to 2 weeks storage at $4{ }^{\circ} \mathrm{C}$ with the appearance of only a minor peak (less than $20 \%$ of total protein) corresponding to the CED-9 $\Delta \mathrm{N} \Delta \mathrm{C}$ protein in the size-exclusion profile upon rechromatography (data not shown).

We were similarly able to express and purify a complex of the NB-ARC/CED- $9 \Delta \mathrm{N} \Delta \mathrm{C}$, indicating that the CARD of CED4 is dispensable for binding to CED-9 (Figure 2d) This is consistent with previous reports. ${ }^{10}$ Interestingly, deletion of just five residues from the C-terminus of CED-4, however, prevented production of soluble complex.

\section{Stoichiometry of the CED-4/CED-9 $\mathbf{N} \Delta \mathrm{C}$ complex}

Coomassie Blue staining of the CED-4/CED-9 $\Delta \mathrm{N} \Delta \mathrm{C}$ complex (Peak II in Figure 2a) on SDS-PAGE gels suggested that the ratio of CED-4 to CED- $9 \Delta \mathrm{N} \Delta \mathrm{C}$ may be greater than $1: 1$, as the CED-4 band appeared significantly more intense (Figure 2b). This was the case whether the complex was isolated using the Nickel-affinity column alone, or in conjunction with gel-filtration chromatography.

To perform a more quantitative analysis of the stoichiometry of the protein complex, it was subjected to six cycles of aminoterminal sequencing. Accurate values for amino-acid abun- dance on each cycle could be readily obtained for all amino acids except aspartates due to technical limitations. The ratio of abundance of CED-9 residues to CED-4 residues was very close to a stoichiometric $1: 1$ ratio (Table 1 ). This suggests that the staining pattern observed on the SDS-PAGE gel may be due to preferential staining of CED-4 or poor staining of CED-9. Such anomalous staining has been reported for other proteins, such as certain surface proteins of Candida albicans. $^{25}$

\section{Size and solution properties of the CED-4/CED- $9 \Delta \mathbf{N} \Delta \mathrm{C}$ complex}

The majority of the purified protein complex in more than 10 different preparations eluted at a retention time (Peak II, Figure 2a) on gel-filtration consistent with a complex of approximately $180-200 \mathrm{kDa}$. This mass estimate, determined from calibration curves on several different columns (e.g. see inset, Figure 2a), together with the stoichiometry data (Table 1), suggested that the complex might be a heterotetramer consisting of two molecules each of CED-4 and CED- $9 \Delta \mathrm{N} \Delta \mathrm{C}$, for which the calculated mass is $175 \mathrm{kDa}$. The apparent size on gel filtration was the same regardless of whether the FLAG tag was present at the amino terminus of the CED- $9 \Delta N \Delta C$, indicating that artificial dimerisation through the FLAG tag was not responsible for the formation of the complex (data not shown).

To get a more accurate assessment of the size of the complex, analytical ultracentrifugation was performed. Sedimentation velocity studies of the complex were initially conducted in Tris-buffered solution at a total protein concentration of $1.0 \mathrm{mg} / \mathrm{ml}$. The absorbance versus radial position profiles are plotted at 6 min intervals in Supplementary Figure 1b. Continuous size-distribution analysis of this data yields an excellent fit to a predominantly single species with a sedimentation coefficient $\left(s_{20, w}\right)$ of $7.5 \mathrm{~S}$ (Supplementary Figure 1c), an apparent molar mass of $159 \mathrm{kDa}$ and frictional ratio of 1.40 . This suggests that the CED-4/CED- $9 \Delta N \Delta C$ complex may exist as either a $2: 1$ or $2: 2$ CED-4/CED$9 \Delta \mathrm{N} \Delta \mathrm{C}$ complex. Therefore, to confirm the quaternary structure of the CED-4/CED- $9 \Delta \mathrm{N} \Delta \mathrm{C}$ complex, sedimentation equilibrium experiments, which are independent of molecular shape estimates and therefore give a more robust measure of molecular mass, ${ }^{26}$ were also conducted at an initial protein concentration of $1.0 \mathrm{mg} / \mathrm{ml}$ (Supplementary Figure $1 \mathrm{~d}-\mathrm{f}$ ). The nonlinear least-squares best-fit yielded a molar mass of $180 \pm 3.8 \mathrm{kDa}$, in excellent agreement with the theoretical heterotetrameric mass of a $2: 2$ CED-4/CED-9 $\Delta \mathrm{N} \Delta \mathrm{C}$ complex $(175 \mathrm{kDa})$.

Table 1 Amino terminal sequencing of the CED-4/CED-9 complex

\begin{tabular}{lcccc}
\hline Cycle & $\mathbf{1}$ & $\mathbf{3}$ & $\mathbf{5}$ & $\mathbf{6}$ \\
\hline CED-4 residue (yield) (pmol) & Gly (10.4) & His (5.7) & His (9.4) \\
CED-9 residue (yield) (pmol) & Ala (10.2) & Leu (4.5) & Tyr (9.3)
\end{tabular}

Amino acid yields on each sequencing cycle are presented except for cycles 2 and 4 where aberrantly high yields of aspartic acid present in CED-9 was obtained. The sequences are those of the tagged recombinant proteins rather than their native counterparts in which the amino terminal six residues of hexahistidine-tagged $C E D-4$ is GSHHHH and of FLAG-tagged CED-9 is ADLDYK 

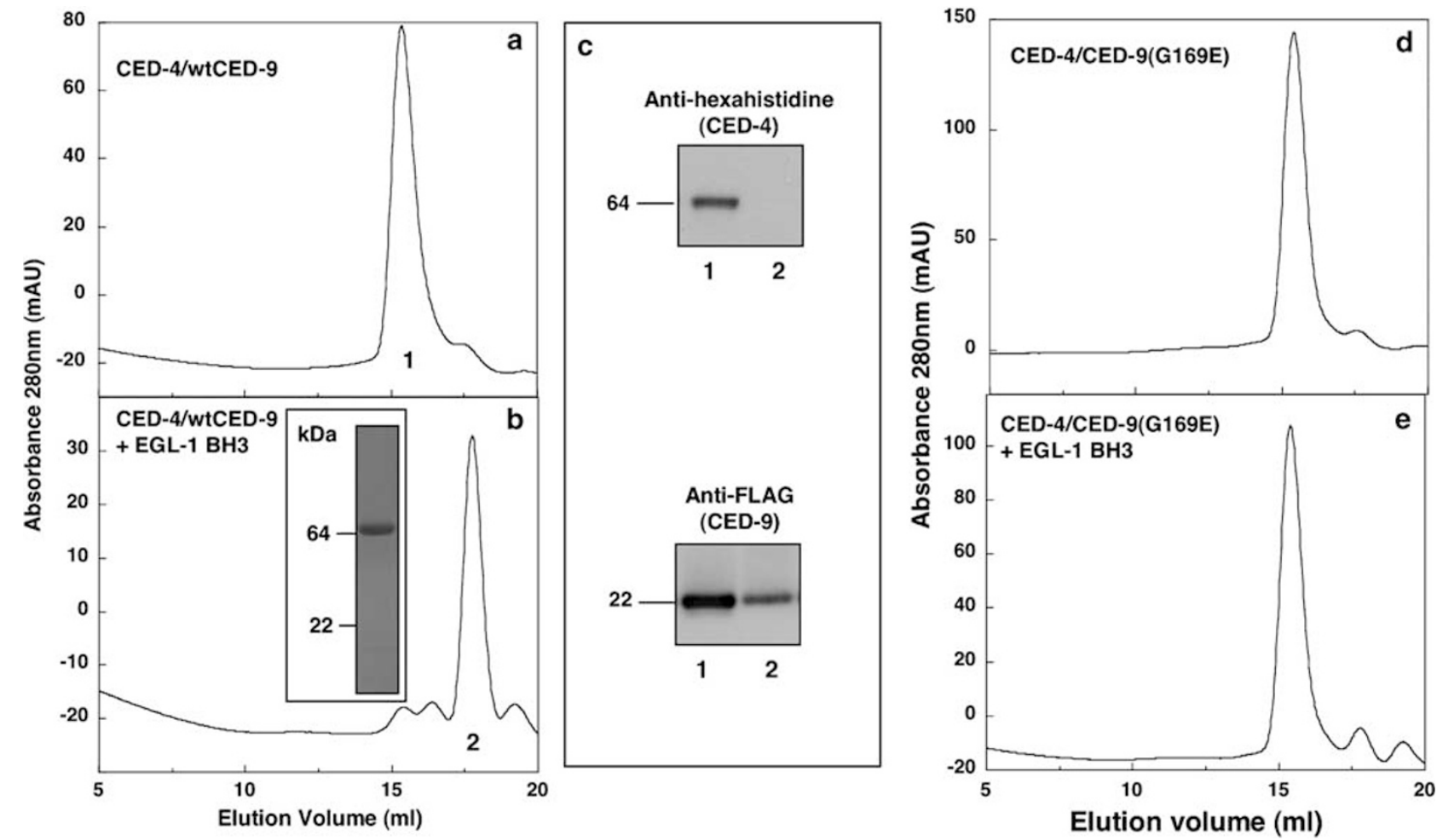

Figure 3 EGL-1 BH3 domain-induced dissociation of CED-4/CED-9 complex. CED-4 in complex with wild-type CED-9 (a, b) or a gain-of-function mutant CED-9 $(\mathrm{G} 169 \mathrm{E})(\mathbf{d}, \mathbf{e})$ was incubated alone $(\mathbf{a}, \mathbf{d})$ or in the presence of a synthetic peptide spanning the EGL-1 BH3 $(\mathbf{b}, \mathbf{e})$ before gel-filtration chromatography. Note the shift of the retention position of Peak 1 in (a) to a smaller sized protein in Peak 2 in (b). The inset in (b) shows a Commasie-stained gel of the insoluble protein removed prior to chromatography. Only protein of the size of CED-4 was present. (c) The identity of the proteins in the two major peaks was confirmed by Western blot analysis. Peak 1 contains both the hexahistidine-tagged CED-4 and FLAG-tagged CED-9 proteins, while Peak 2 contains only CED-9. (d, e) Addition of the EGL-1 BH3 peptide did not affect the complex formed between a gain-of-function mutant of CED9 (G169E) and CED-4

\section{EGL-1 BH3 domain displaces CED-4 from CED-9}

The current model for the apoptosis pathway in worms proposes that binding of the BH3-only protein EGL-1 to CED-9 results in displacement of bound CED-4. . $^{3,12,15}$ If this is correct, we predict that the CED-4/CED-9 complex formed in vitro (Figure 2a, Peak II) would be disrupted by EGL-1. When the purified CED-4/CED-9 $\Delta N \Delta C$ complex was incubated with a synthetic 26-mer peptide encompassing the $\mathrm{BH} 3$ domain of EGL-1, a visible precipitate formed, which was removed by centrifugation. Gel-filtration chromatography of the soluble material demonstrated dissociation of CED-4 from CED$9 \Delta \mathrm{N} \Delta \mathrm{C}$, with essentially no protein detected where the untreated complex normally elutes (Figure 3a,b). Only a peak corresponding to an $\sim 25 \mathrm{kDa}$ protein was detected, which on Western blotting was shown to contain FLAG-tagged CED$9 \Delta \mathrm{N} \Delta \mathrm{C}$ (Figure 3c), but not CED-4. Instead, all of the CED-4 appeared to be contained in the insoluble pellet removed by centrifugation prior to chromatography (see inset, Figure 3b).

Importantly, the release of the CED-4 from the complex appeared to be dependent upon a specific interaction of the EGL-1 BH3 peptide with wild-type CED-9. A single point mutation in CED-9, substituting the highly conserved glycine at position 169 with glutamate, which has been reported to effect EGL-1 binding, ${ }^{8,15}$ completely prevented the EGL-1 $\mathrm{BH} 3$ domain peptide from displacing CED-4 (Figure 3d,e). However, the ability of this mutant CED-9 to bind CED-4 was unaffected (Figure $3 d$ ), which may explain why this mutant is a more potent inhibitor of cell death ${ }^{4}$ since it can no longer be restrained by EGL-1.

Similar results were obtained using isothermal titration microcalorimetry (Figure 4). In these studies, EGL-1 peptide was titrated into the CED-4/CED-9 $\Delta N \Delta C$ complex. In the initial EGL-1 peptide injections into the CED-4/CED-9 $\Delta N \Delta C$ containing solution, heat was released (Figure $4 \mathrm{a}$ ), indicating a binding event between the peptide and the complex. However, a pronounced baseline shift was then observed upon subsequent additions of peptide. This shift may be due to aggregation/precipitation of CED-4 released from the complex as the solution removed from the isothermal titration calorimetry (ITC) cell at the completion of the titration was noticeably turbid. SDS-PAGE analysis of the pellet postcentrifugation confirmed that it contained predominantly CED-4 (data not shown). The system is thermodynamically complex involving several potential reactions all of which release or absorb heat (i.e. EGL-1 peptide binds CED-9, CED-4 release from CED-9, CED-4 oligomerisation/precipitation), and hence quantitative analysis of the data is difficult.

However, the results provide qualitative evidence that aggregation of CED-4 occurs very soon after dissociation from CED-9 (Figure 4a). When a complex containing the CED-9 $\Delta N \Delta C$ (G169E) was similarly analysed, no initial heat release or significant baseline shift was observed (Figure $4 b$ ) This confirms our gel-filtration results that EGL-1 BH3 could not bind mutant CED-9 $\Delta N \Delta C$ (G169E) (Figure 3d,e). 

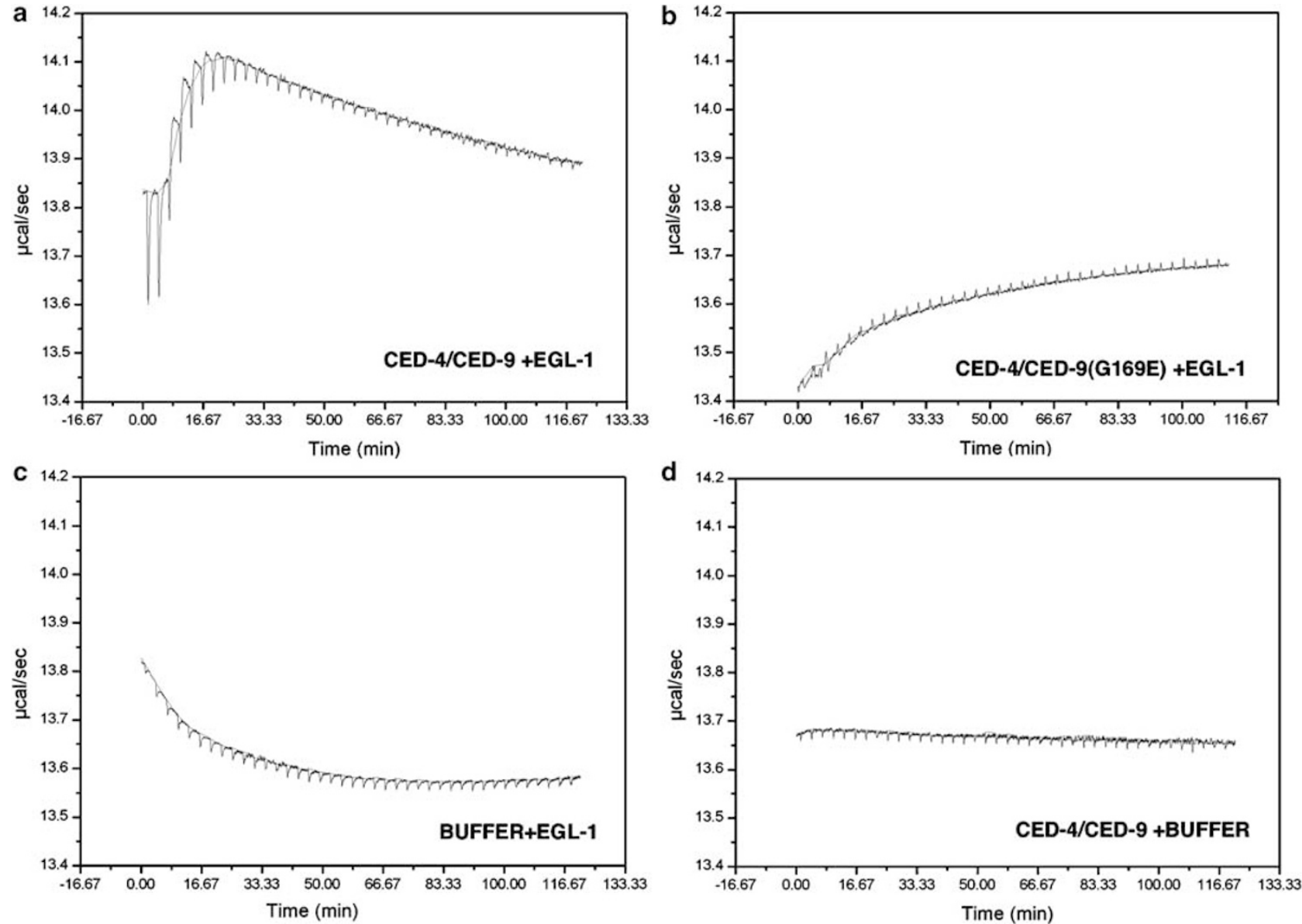

Figure 4 CED-4/CED-9 complex dissociation demonstrated by isothermal titration calorimetry (ITC). Raw data from isothermal calorimetry experiments with CED-4/ CED-9 or CED-4/CED-9 (G169E) complexes. EGL-1 BH-3 peptide was titrated into solution (a) containing CED-4/CED-9, (b) CED-4/CED-9 (G169E), or (c) buffer only. In (d), buffer only was titrated into solution containing CED-4/CED-9 complex

\section{Unlike worm BH3-only proteins, mammalian BH3-only proteins cannot disrupt the CED-4/CED-9 complex}

Using isothermal titration calorimetry, we were able to directly determine the affinity of EGL-1 BH3 peptide for free (uncomplexed) CED-9 $\Delta \mathrm{N} \Delta \mathrm{C}$. The $K_{\mathrm{D}}$ for this interaction was approximately $25 \mathrm{nM}$, consistent with a previously reported value $(6 \mathrm{nM})$ measured by ITC using a comparable EGL-1 peptide. ${ }^{16}$ Recently, a second BH3-only protein, CED-13, was discovered in the worm. ${ }^{27}$ Its $\mathrm{BH} 3$ domain sequence shows significant homology with that of EGL-1 (Figure 7), and overexpression of CED-13 in C. elegans promotes apoptosis. ${ }^{27}$ We therefore compared the ability of CED-13 to bind CED-9 and found that the affinity of a peptide spanning this $\mathrm{BH} 3$ domain was approximately four-fold lower $(\sim 100 \mathrm{nM})$ than that of the EGL-1. Consistent with this, we observed that the CED-13 BH3 peptide can also disrupt the CED-4/CED$9 \Delta \mathrm{N} \Delta \mathrm{C}$ complex, but with lower efficiency as demonstrated by a significant proportion of the complex remaining after treatment (Figure 5b)

Since both worm BH3-only proteins can displace CED-4 from CED-9, the evolutionary conservation of the cell death pathways prompted us to test if mammalian $\mathrm{BH}$-only proteins can also trigger this dissociation. As mammalian $\mathrm{Bcl}-2$ can function in worms, ${ }^{4,28}$ we wondered if mammalian $\mathrm{BH}$-only proteins such as Bim, which can bind to all known mammalian prosurvival proteins, could substitute for worm EGL-1. We found instead that Bim $\mathrm{BH} 3$ peptide could not bind CED$9 \Delta \mathrm{N} \Delta \mathrm{C}$ in direct binding studies, using isothermal titration calorimetry (data not shown), and consistent with this, $\mathrm{Bim} \mathrm{BH} 3$ peptide did not disrupt the complex formed between CED-4 and CED-9 $\Delta N \Delta C$ (Figure 5c). Furthermore, synthetic peptides corresponding to the $\mathrm{BH} 3$ domain sequence from several other mammalian BH3-only proteins, Bid, Bad, Noxa or Puma, did not cause any complex dissociation (data not shown).

To determine whether complex dissociation could involve more than just the $\mathrm{BH} 3$ domain sequence, we examined the ability of the promiscuous-binding full-length $\mathrm{Bim}_{\mathrm{S}}$ protein to interact with the CED-4/CED-9 complex. In an initial experiment, bacterially expressed recombinant full-length $\mathrm{Bim}_{\mathrm{S}}$ protein was used in place of the $\mathrm{BH} 3$ domain peptide. This protein, as with the peptide, was unable to dissociate or interact with the purified CED-4/CED-9 complex as determined by both gel-filtration and ITC experiments (data 


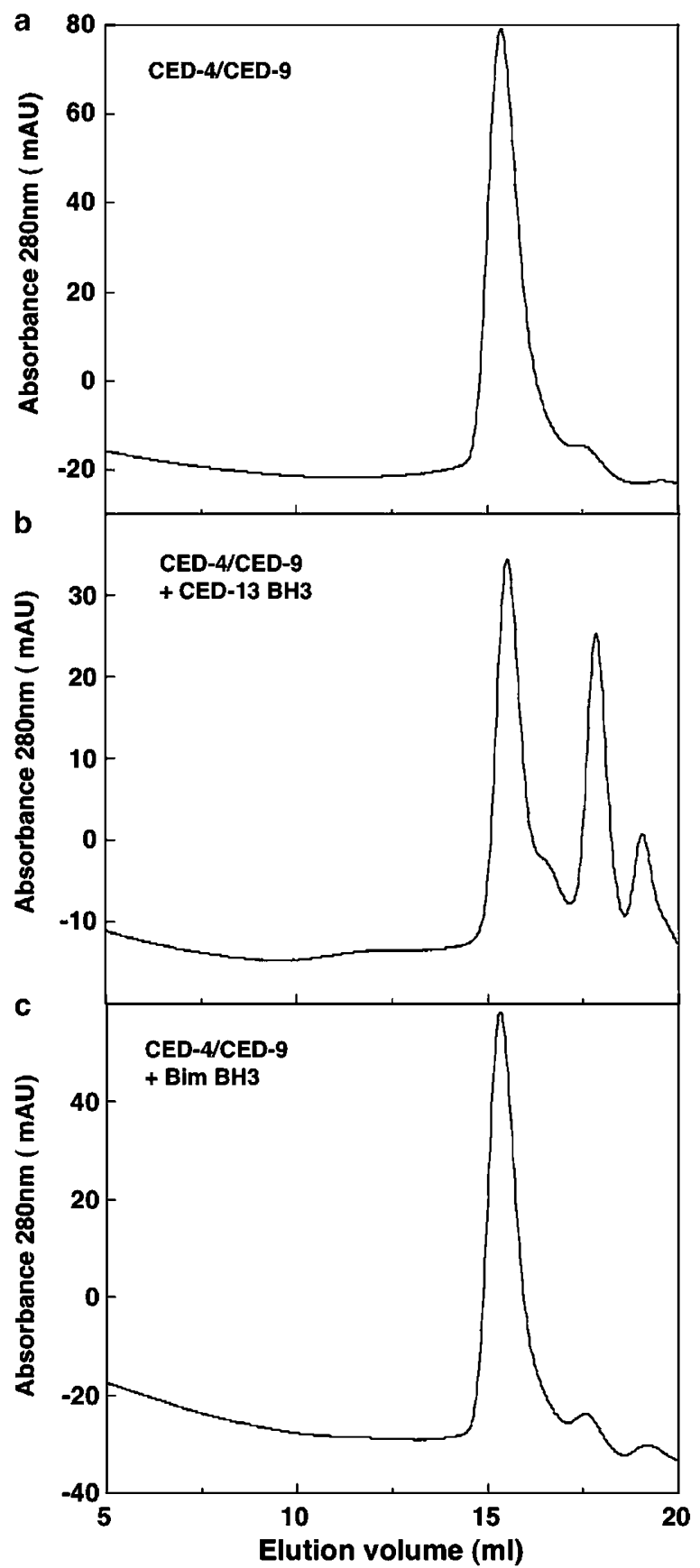

Figure 5 C. elegans CED-13 BH3, but not Bim BH3 dissociate CED-4 from CED-9. The purified CED-4/CED-9 complex was incubated (a) alone, or with synthetic peptides corresponding to (b) $\mathrm{CED}-13 \mathrm{BH} 3$ or (c) Bim $\mathrm{BH} 3$ prior to gelfiltration chromatography. Note the partial complex dissociation with CED-13 BH3 peptide, whereas addition of Bim $\mathrm{BH} 3$ had no impact

not shown). This was confirmed in co-immunoprecipitation experiments (Figure 6). In these experiments, expression of EGL-1 prevented association of CED-4 with CED-9. However, consistent with studies using bacterially- expressed recombinant material, expression of $\mathrm{Bim}_{\mathrm{s}}$ had no effect on complex formation/dissociation (Figure 6). Taken together, these binding studies confirm the selectivity of worm BH3-proteins (EGL-1 and CED-13) for CED-9.

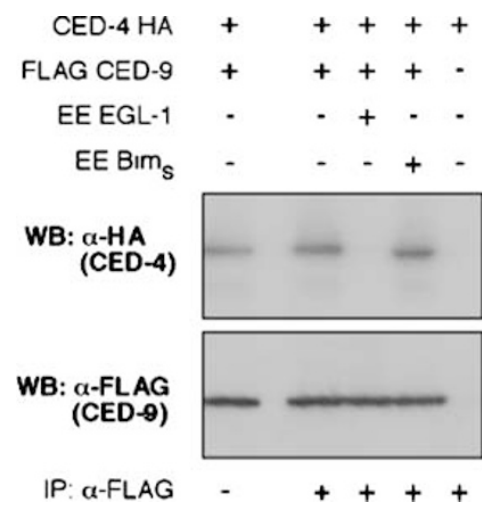

Figure 6 C. elegans EGL-1, but not human Bim , dissociate CED-4 from CED-9. Equivalent lysates prepared from 293T cells cotransfected with constructs encoding HA-tagged CED-4 and FLAG-tagged CED-9 and either EE-tagged CED9 or EE-tagged Bim were immunoprecipitated with anti-FLAG antibodies and immunoblotted with both anti-HA (upper panel) or anti-FLAG (lower panel) antibodies. EGL-1 expression disrupts the CED-4/CED-9 complex, but Bim $\mathrm{s}_{\mathrm{s}}$ was unable to do so

\section{Discussion}

In $C$. elegans, the life-or-death fate of a cell is dependent upon whether the adapter protein CED-4 is sequestered by CED-9. In this manuscript we have shown for the first time that the CED-4/CED-9 complex can exist as a heterotetramer in aqueous solution, with the size and stoichiometry of the complex determined from gel-filtration chromatography (Figure 2), N-terminal sequencing (Table 1) and analytical ultracentrifugation (Supplementary Figure 1). This complex is (coexpressed) at milligram per litre quantities in $E$. coli and is highly soluble. In contrast, attempts to purify similar levels of CED-4 alone were hindered by the protein's insolubility and tendency to aggregate into inclusion bodies. Previously, the expression of soluble GST-fusions of CED-4 has been reported, ${ }^{8,14,24}$ although the amounts of protein produced in these studies is unclear, while other attempts to coexpress CED-4 and CED-3 resulted only in the production of insoluble proteins. ${ }^{29}$ While we cannot eliminate the possibility that the CED-4/CED-9 complex known to be associated with the mitochondrial membrane in the worm exists in a different oligomeric form to that described here for the E. coli-derived complex, our biochemical data for different complexes, including mutants, are consistent with the features of the protein complex characterised previously. $5,6,8-10,12,15$

For example, we have shown that the formation of the complex is not dependent on the presence of the CARD of CED-4, consistent with the requirement that it be free to recruit CED-3 to a trimolecular complex of CED-3/CED-4/CED-9. ${ }^{7}$ This result agrees with other studies using yeast two-hybrid assays showing a strong interaction between CED-9 and CED-4 with its CARD deleted. ${ }^{10}$ Importantly, we also demonstrated that the heterotetrameric CED-4/CED-9 $\Delta \mathrm{N} \Delta \mathrm{C}$ complex dissociated upon incubation with a synthetic peptide corresponding to the $\mathrm{BH} 3$ domain of $\mathrm{EGL}-1$ providing evidence that the complex produced here in $E$. coli behaves functionally in a manner similar to that reported in transfected cells (Figure 6) ${ }^{12,15}$ and in worms. ${ }^{5}$ Furthermore, we demonstrated that introduction of the G169E gain-of-function mutation into CED-9 $\Delta \mathrm{N} \Delta \mathrm{C}$ prevented $\mathrm{EGL}-1 \mathrm{BH} 3$ peptide-induced 


\begin{tabular}{|c|c|c|c|c|c|c|c|c|c|c|c|c|c|c|c|c|c|c|c|c|c|c|c|c|c|c|}
\hline EGL-1 & I & S & S & 1 & G & $Y$ & $E$ & 1 & G & S & K & L & A & A & M & C & D & D & $F$ & D & A & Q & M & M & S & $Y$ \\
\hline CED-13 & $\bar{S}$ & $\mathrm{~N}$ & $\bar{T}$ & V & $E$ & $Y$ & $\mathrm{~N}$ & 1 & G & 8 & $\mathrm{~K}$ & L & $T$ & V & $M$ & C & D & $E$ & $F$ & D & $\mathrm{S}$ & $E$ & $\mathrm{~L}$ & $M$ & S & $Y$ \\
\hline Bim & D & $M$ & $R$ & $P$ & $\mathrm{E}$ & 1 & W & I & A & Q & $\mathrm{E}$ & $\bar{L}$ & $\mathrm{R}$ & $\mathrm{R}$ & I & G & D & $\mathrm{E}$ & $F$ & $\mathrm{~N}$ & A & $\bar{Y}$ & $\bar{Y}$ & A & $\mathrm{R}$ & \\
\hline Bid & Q & $E$ & $D$ & 1 & 1 & $\mathrm{R}$ & $\mathrm{N}$ & 1 & A & $\mathrm{R}$ & $\mathrm{H}$ & L & A & Q & V & $\mathrm{G}$ & D & S & $M$ & D & $R$ & $S$ & I & $P$ & $P$ & \\
\hline $\mathrm{Bad}$ & $\mathrm{N}$ & L & W & A & A & $Q$ & $\mathrm{R}$ & $Y$ & G & $\mathrm{R}$ & $E$ & L & $\mathrm{R}$ & $\mathrm{R}$ & $M$ & $S$ & D & $E$ & $\mathrm{~F}$ & V & D & S & $\mathrm{F}$ & K & K & \\
\hline Noxa & $\mathrm{P}$ & A & $E$ & $\mathrm{~L}$ & E & V & E & C & $A$ & $\mathrm{~T}$ & $Q$ & L & R & $\mathrm{R}$ & $\bar{F}$ & G & D & $\mathrm{K}$ & $\mathrm{L}$ & $N$ & $\mathrm{~F}$ & $\mathrm{R}$ & Q & K & L & \\
\hline Puma & $E$ & E & $Q$ & W & A & $\mathrm{R}$ & E & 1 & G & A & Q & L & $\mathrm{R}$ & $\mathrm{R}$ & $\mathrm{M}$ & $A$ & D & D & L & $\mathrm{N}$ & A & Q & Y & E & R & \\
\hline
\end{tabular}

Figure 7 Sequences of $\mathrm{BH} 3$ peptides used. The $\mathrm{BH} 3$ domains of the indicated $\mathrm{BH} 3$-only proteins were synthesised as 26 -mers. Shaded residues indicate identity with the EGL-1 sequence

release of CED-4 from the complex as shown previously. ${ }^{5}$ In addition, no binding was detected between the EGL-1 BH3 peptide and the complex involving this CED-9 $\Delta \mathrm{N} \Delta \mathrm{C}(\mathrm{G} 169 \mathrm{E})$ mutant in our ITC studies. These results agree with the previously observed failure of CED-4 to be released from the mitochondria in cells expressing this CED- 9 mutant, ${ }^{5}$ and structural studies that show that the G169E substitution occludes the BH3-binding groove. ${ }^{14}$

Our experiments also support observations by others that, in the absence of CED-9, CED-4 self-associates. ${ }^{5,24}$ Using purified recombinant proteins, we have shown that following EGL-1 BH3 peptide-induced release of CED-4 from CED-9, CED-4 forms an insoluble aggregate. The ITC studies also suggest that this aggregation occurs very soon after EGL-1 $\mathrm{BH} 3$ peptide-induced release from CED-9. This tendency for CED-4 to aggregate/self-associate may explain why expression of high levels of soluble CED-4 in E. coli was not possible. However, it may be the case that this aggregation process would be less pronounced or, at least, more controlled if CED-4 were bound to CED-3, as may be the case in cells.

We also examined the ability of $\mathrm{BH} 3$ domains from proteins other than EGL-1 (Figure 5) to dissociate the CED-4/CED$9 \Delta \mathrm{N} \Delta \mathrm{C}$ complex. The $\mathrm{BH} 3$ domain sequence from another nematode protein, CED-13, was able to displace CED-4 from CED-9, although it was less effective than the EGL-1 peptide. This weaker dissociating activity was reflected in the approximately four-fold lower affinity of the peptide for CED-9. CED-13 binding to CED-9 in C. elegans has been reported, although the proapoptotic phenotype of CED-13 is apparently weaker than that of EGL-1. ${ }^{27}$ The weaker affinity of CED-13 for CED-9 $\Delta \mathrm{N} \Delta \mathrm{C}$ compared to that of EGL-1 may provide a partial rationale for this observation. Interestingly, $\mathrm{BH} 3$ domain sequences from the mammalian $\mathrm{BH} 3$-only proteins Bim, Puma, Noxa, Bad, and Bid were completely ineffective at dissociating the complex, consistent with the absence of binding of Bim to free CED- $9 \Delta \mathrm{N} \Delta \mathrm{C}$ in our ITC studies. We have previously shown that both Bim and Puma can bind with high affinity (dissociation equilibrium constants in the low nanomolar range) to all known mammalian Bcl-2 family proteins, while Noxa, Bad and Bid have more restricted specificities. ${ }^{30}$ Among the central 16 residues at the core of the $\mathrm{BH} 3$ domains illustrated in Figure 7, the EGL-1 sequence is preserved at 10 of these positions in one or more of the mammalian proteins. If the $\mathrm{BH} 3$ domains of all known human $\mathrm{BH} 3$-only proteins ${ }^{30}$ are included in the comparison (although not all have been assayed here), the number increases to 13 (or 14 if the Cys for Ser substitution is discounted). Thus, a significant residual of the worm EGL-1 sequence persists in the $\mathrm{BH} 3-$ only proteins in mammals, but none of those tested here can displace CED-4 from CED-9. Hence, this inability of $\mathrm{BH} 3$ domain sequences from mammalian $\mathrm{BH} 3-$ only proteins to displace CED-4 further illustrates aspects of the specificity between $\mathrm{BH} 3$ domains and prosurvival molecules.

The observation that the CED-4/CED-9 $\mathrm{N} \Delta \mathrm{C}$ complex is heterotetrameric has a number of implications. Site-directed mutagenesis studies of CED-9 indicate that residues in a surface patch adjacent to the $\mathrm{BH} 3$ domain-binding groove on CED-9 are involved in the interaction with CED- $4 ;{ }^{14}$ however, our data suggest that a yet-to-be characterised binding surface on either or both of the components is involved in dimerisation of the CED-4/CED-9 complex. Further, our data indicate that this binding surface involves neither the membrane anchor nor the N-terminal 67 residues of CED-9. The absence of evidence for a dimer of CED-9 in solution suggests that CED-4 may mediate dimerisation of the CED-4/ CED-9 $\Delta \mathrm{N} \Delta \mathrm{C}$ complex. In that case, the NB-ARC would be implicated in the homodimerisation of CED-4 as the complex can be formed in the absence of the CED-4 CARD. Furthermore, our finding that deletion of just five residues from the C-terminus of CED-4 prevented production of soluble complex suggests that the interface for complex formation includes the C-terminus of CED-4. In the APAF-1 structure, the C-terminal residues are located on a short helix at the opposite end of the molecule to the N-terminus and, importantly, are quite distinct from the other four protein domains. ${ }^{23}$ Hence, the inability to produce soluble protein with the short C-terminal deletion is unlikely due to failure of the CED-4 proteins to fold, but is more likely due to a failure in the assembly of the complex.

It is known that CED-3 can bind to the CED-4/CED-9 complex ${ }^{7,31}$ and that activation of CED-3 occurs following displacement of CED-9 and oligomerisation of CED-4. We have shown that the heterotetramer does not depend on the presence of the N-terminal CARD of CED-4, which suggests that in this complex it is 'available' to bind its cognate CARD on CED-3. If this model holds for a ternary CED-3/CED-4/CED-9 complex anchored via CED-9 to the mitochondrial membrane, then that complex would contain two molecules of CED-3, apparently held in such a way that autoactivation is inhibited. We have preliminary electron microscopy data showing that the negatively stained CED-4/CED-9 complex is compact (100-120 $\AA$ in diameter). Based on the molecular dimensions of APAF-1, this suggests a side-by-side arrangement of the CED-4 protomers in the heterotetramer, although no information is available on the details. In a recent paper by Chao et al., ${ }^{32}$ it was elegantly demonstrated that dimerisation of caspase- 9 alone is not sufficient for full activity (compared to APAF-1activated caspase-9). Instead, an induced conformational 
change may be more important. Thus, even a head-to-head or parallel alignment (i.e. with the CED-4 CARD's aligned) may not suffice to activate CED-3 without the stimulus of EGL-1, and the resulting reorganisation of CED-4/CED-3.

We postulate an active role for CED-3 in controlling the oligomerisation of CED-4, because in its absence, CED-4 forms insoluble aggregates on release from CED-9. Future structural studies based on the results we have described should provide further insight into the molecular mechanism of this activation process.

\section{Materials and Methods}

\section{Plasmid construction}

The CED-4/CED-9 complex was coexpressed using the pET DUET-1 dual expression vector (Novagen). The wild-type or mutant ced-4S cDNA's were subcloned into the first multiple cloning site such that an $\mathrm{N}$-terminal hexahistidine tag was added to the protein, while the wild-type or mutant FLAG-tagged ced-9 cDNA's were subcloned into the second multiple cloning site. Hexahistidine-tagged CED-9 (amino acids 68-251) was produced using the $\mathrm{pET} 15 \mathrm{~b}$ vector (Novagen). Mutagenesis of both CED-4 and CED- 9 was performed using the method of Kunkel et al. ${ }^{33}$ All constructs were confirmed by bidirectional automated DNA sequencing.

\section{Protein expression and purification}

Proteins were expressed in BL-21(DE3) pLysS cells. For the CED-4/CED-9 coexpression, cells were grown from an overnight culture to an $\mathrm{OD}_{600}$ of $0.6-0.8$ at $37^{\circ} \mathrm{C}$. Expression of proteins was then induced with $500 \mu \mathrm{M}$ isopropyl- $\beta$-D-thiogalactopyranoside for $5 \mathrm{~h}$ at $25^{\circ} \mathrm{C}$ after which cells were pelleted and stored at $-80^{\circ} \mathrm{C}$ until required. Uncomplexed CED-9 was expressed by induction at $37^{\circ} \mathrm{C}$ for $3 \mathrm{~h}$.

To purify the proteins, cell pellets were thawed and homogenised using an Avestin EmulsiFlex homogeniser in lysis buffer $(20 \mathrm{mM}$ Tris- $\mathrm{HCl}, \mathrm{pH}$ 8.0, $150 \mathrm{mM} \mathrm{NaCl}, 10 \mathrm{mM}$ 2-mercaptoethanol: TBS/2ME). Following centrifugation to remove cell debris, the supernatant was filtered and then pumped onto a $1 \mathrm{ml} \mathrm{Hi-Trap} \mathrm{(Amersham} \mathrm{Biosciences)} \mathrm{chelating} \mathrm{column}$ charged with nickel. After washing the column with lysis buffer containing $20 \mathrm{mM}$ imidazole, the protein was eluted with lysis buffer containing $250 \mathrm{mM}$ imidazole. The eluate was then further purified by gel-filtration chromatography on a Superdex 200 16/60 column (Amersham) equilibrated and run in lysis buffer at $1 \mathrm{ml} / \mathrm{min}$.

\section{SDS-PAGE and Western blot analysis}

Proteins were boiled in Laemmli sample buffer for $3 \mathrm{~min}$ prior to electrophoresis on precast 4-20\% polyacrylamide gradient gels (Invitrogen). Gels were either stained directly in a Coomasie Brilliant Blue solution or proteins transferred to PVDF membranes for Western blot analysis. Membranes were probed using either anti-hexahistidine (Santa Cruz Biotechnology) or anti-FLAG M2 antibodies (Sigma) followed by anti-rabbit or anti-mouse horseradish peroxidase-conjugated secondary antibodies. Proteins were then visualised by enhanced chemiluminescence (Amersham Biosciences).

\section{CED-4/CED-9 complex dissociation assays}

Studies on the dissociation of the CED-4/CED-9 complex were performed by incubation of $50 \mu \mathrm{g}$ of protein $(0.5 \mathrm{mg} / \mathrm{ml})$ with a two-fold molar excess of synthetic $\mathrm{BH} 3$ domain peptide (supplied by Mimotopes) in a total volume of $200 \mu \mathrm{l}$ for $1 \mathrm{~h}$ at room temperature. The reaction mixture was then centrifuged for $5 \mathrm{~min}$ at $13000 \mathrm{rpm}$ in a bench-top microfuge prior to chromatography on a Superose $610 / 30$ column equilibrated and run in TBS $/ 2 M E$ at $0.5 \mathrm{ml} / \mathrm{min}$.

\section{Isothermal titration microcalorimetry}

Isothermal titration microcalorimetry (ITC) studies were performed using a MicroCal VP-ITC instrument. Proteins were diluted to $15 \mu \mathrm{M}$ in TBS/2ME and peptides (prepared in the same buffer from $2 \mathrm{mM}$ stocks) were titrated from a $120 \mu \mathrm{M}$ solution. All experiments were performed at $25^{\circ} \mathrm{C}$. Data analysis was performed using the MicroCal Origin software.

\section{Analytical ultracentrifugation}

Sedimentation experiments were conducted in a Beckman model XL-A analytical ultracentrifuge at a temperature of $20^{\circ} \mathrm{C}$. Samples dissolved in $20 \mathrm{mM}$ Tris, $150 \mathrm{mM} \mathrm{NaCl}, 1 \mathrm{mM}$ DTT, pH 8.0 were loaded into a conventional double sector quartz cell and mounted in a Beckman 4-hole An-60 Ti rotor. For sedimentation velocity experiments, $380 \mu \mathrm{l}$ of sample $(1.0 \mathrm{mg} / \mathrm{ml})$ and $400 \mu \mathrm{l}$ of reference solution were centrifuged at a rotor speed of $40000 \mathrm{rpm}$, and the data were collected at a single wavelength $(280 \mathrm{~nm})$ in continuous mode, using a time interval of $300 \mathrm{~s}$ and a step-size of $0.003 \mathrm{~cm}$ without averaging. For sedimentation equilibrium experiments, $100 \mu \mathrm{l}$ of sample $(1.0 \mathrm{mg} / \mathrm{ml})$ and $120 \mu \mathrm{l}$ of reference were employed and the data were collected at a wavelength of $290 \mathrm{~nm}$, rotor velocity of 10000 or $16000 \mathrm{rpm}$, using a stepsize of $0.001 \mathrm{~cm}$ with 10 averages until sedimentation equilibrium was attained $(\sim 24 \mathrm{~h})$. To estimate the signal due to nonsedimenting contaminants, high-speed depletion was performed at $40000 \mathrm{rpm}$ for $5 \mathrm{~h}$ following sedimentation equilibrium, and the resulting baseline offset $(E)$ was calculated by averaging the absorbance over a radial range of $0.1 \mathrm{~cm}$ in the plateau region adjacent to the sample meniscus. For all samples, the values for $E$ represented $<5 \%$ of the initial absorbance. Solvent density $(1.005 \mathrm{~g} / \mathrm{ml}$ at $20^{\circ} \mathrm{C}$ ) and viscosity $(1.021 \mathrm{cp})$, as well as estimates of the partial specific volume $(0.734 \mathrm{ml} / \mathrm{g})$ and hydration $(0.402 \mathrm{~g} / \mathrm{g})$ of the CED-4/CED-9 $\Delta \mathrm{N} \Delta \mathrm{C}$ complex were computed using the program SEDNTERP. ${ }^{34}$ Sedimentation velocity data at multiple time points were fitted to either a noninteracting discrete species model of up to three components or a continuous sizedistribution mode ${ }^{35}$ using the program SEDFIT, which is available at www.analyticalultracentrifugation.com. Sedimentation equilibrium data at multiple speeds were globally fitted to single discrete species model by employing the program SEDPHAT, ${ }^{36}$ which is similarly available.

\section{$\mathrm{N}$-terminal amino-acid sequencing}

$\mathrm{N}$-terminal amino-acid sequencing was performed using a Hewlett Packard G1000A protein sequencer.

\section{Co-immunoprecipitations}

293T cells were transiently cotransfected with pcDNA3 vectors encoding HA-tagged CED-4 and FLAG-tagged CED-9 and either EE-tagged-EGL-1 or EE-tagged Bim $\mathrm{S}$, both in pEF vectors. At $24 \mathrm{~h}$ post-transfection, CED-4/ CED-9 complexes were immunoprecipitated using a mouse M2 anti-FLAG antibody (Sigma). Following SDS-PAGE, proteins were transferred onto nitrocellulose membranes and immunoblotted with either rat anti-HA $3 F 10$ (Roche) or FLAG $9 \mathrm{H} 1$ antibodies. $^{37}$ 


\section{Acknowledgements}

We thank Mr Marco Evangelista and Mr Jai Yu for excellent technical assistance and Mr Phil Strike at CSIRO Health Science and Nutrition for the protein sequencing. Our work is supported by the Australian NHMRC (Program Grant 257502 and an RD Wright Fellowship to WDF), Leukemia and Lymphoma Society (Specialized Center of Research 7015-02), Cancer Council Victoria (Fraser Fellowship to PMC), Sylvia and Charles Viertel Charitable Foundation, and Australian Cancer Research Foundation.

\section{References}

1. Horvitz HR (1999) Genetic control of programmed cell death in the nematode Caenorhabditis elegans. Cancer Res. 59 (7 Suppl): 1701s-1706s

2. Yuan JY and Horvitz HR (1990) The Caenorhabditis elegans genes ced-3 and ced-4 act autonomously to cause programmed cell death. Dev. Biol. 138: 33-41

3. Conradt B and Horvitz HR (1998) The C. elegans protein EGL-1 is required for programmed cell death and interacts with the Bcl-2-like protein CED-9. Cell 93: 519-529

4. Hengartner MO and Horvitz HR (1994) C. elegans cell survival gene ced-9 encodes a functional homolog of the mammalian proto-oncogene $b c /-2$. Cell 76: 665-676

5. Chen F, Hersh BM, Conradt B, Zhou Z, Riemer D, Gruenbaum Y and Horvitz HR (2000) Translocation of $C$. elegans CED-4 to nuclear membranes during programmed cell death. Science 287: 1485-1489

6. Yang X, Chang HY and Baltimore D (1998) Essential role of CED-4 oligomerization in CED-3 activation and apoptosis. Science 281: 1355-1357

7. Chinnaiyan AM, Chaudhary D, O'Rourke K, Koonin EV and Dixit VM (1997) Role of CED-4 in the activation of CED-3. Nature 388: 728-729

8. Parrish J, Metters $H$, Chen $L$ and Xue D (2000) Demonstration of the in vivo interaction of key cell death regulators by structure-based design of second-site suppressors. Proc. Nat. Acad. Sci. USA 97: 11916-11921

9. Spector MS, Desnoyers S, Hoeppner DJ and Hengartner MO (1997) Interaction between the $C$. elegans cell-death regulators CED-9 and CED-4. Nature 385: 653-656

10. Ottilie S, Wang Y, Banks S, Chang J, Vigna NJ, Weeks S, Armstrong RC, Fritz LC and Oltersdorf T (1997) Mutational analysis of the interacting cell death regulators CED-9 and CED-4. Cell Death Differ. 4: 526-533

11. Tao W, Walke DW and Morgan JI (1999) Oligomerized Ced-4 kills budding yeast through a caspase-independent mechanism. Biochem. Biophys. Res. Commun. 260: 799-805

12. del Peso L, González VM and Núñez G (1998) Caenorhabditis elegans EGL-1 disrupts the interaction of CED-9 with CED- 4 and promotes CED-3 activation. J. Biol. Chem. 273: 33495-33500

13. Wu D, Wallen HD, Inohara N and Nuñez G (1997) Interaction and regulation of the Caenorhabditis elegans death protease CED-3 by CED- 4 and CED-9. J. Biol. Chem. 272: 21449-21454

14. Yan N, Gu L, Kokel D, Chai J, Li W, Han A, Chen L, Xue D and Shi Y (2004) Structural, biochemical, and functional analyses of CED-9 recognition by the proapoptotic proteins EGL-1 and CED-4. Mol. Cell 15: 999-1006

15. del Peso L, González VM, Inohara N, Ellis RE and Núñez G (2000) Disruption of the CED-9/CED-4 complex by EGL-1 is a critical step for programmed cell death in C. elegans. J. Biol. Chem. 275: 27205-27211

16. Woo JS, Jung JS, Ha NC, Shin J, Kim KH, Lee W and Oh BH (2003) Unique structural features of a BCL-2 family protein CED-9 and bio physical characterization of CED-9/EGL-1 interactions. Cell Death Differ. 10: 1310-1319

17. Muchmore SW, Sattler M, Liang H, Meadows RP, Harlan JE, Yoon HS, Nettesheim D, Chang BS, Thompson CB, Wong S-L, Ng S-C and Fesik SW
(1996) X-ray and NMR structure of human Bcl- $\mathrm{X}_{\mathrm{L}}$, an inhibitor of programmed cell death. Nature 381: 335-341

18. Petros AM, Medek A, Nettesheim DG, Kim DH, Yoon HS, Swift K, Matayoshi ED, Oltersdorf T and Fesik SW (2001) Solution structure of the antiapoptotic protein bcl-2. Proc. Nat. Acad. Sci. USA 98: 3012-3017

19. Liu X, Dai S, Zhu Y, Marrack P and Kappler JW (2003) The structure of a Bcl- $\mathrm{X}_{\mathrm{L}} /$ Bim fragment complex: Implications for Bim function. Immunity 19: 341-352

20. Petros AM, Nettseheim DG, Wang Y, Olejniczak ET, Meadows RP, Mack J, Swift K, Matayoshi ED, Zhang H, Thompson CB and Fesik SW (2000) Rationale for $\mathrm{Bcl}-\mathrm{x}_{\mathrm{L}} / \mathrm{Bad}$ peptide complex formation from structure, mutagenesis, and biophysical studies. Protein Sci. 9: 2528-2534

21. Sattler M, Liang H, Nettesheim D, Meadows RP, Harlan JE, Eberstadt M, Yoon HS, Shuker SB, Chang BS, Minn AJ, Thompson CB and Fesik SW (1997) Structure of $\mathrm{BCl}-\mathrm{x}_{\mathrm{L}}-\mathrm{Bak}$ peptide complex: recognition between regulators of apoptosis. Science 275: 983-986

22. Hengartner MO and Horvitz HR (1994) Activation of C. elegans cell death protein CED-9 by an amino-acid substitution in a domain conserved in Bcl-2. Nature 369: 318-320

23. Riedl SJ, Li W, Chao Y, Schwarzenbacher R and Shi Y (2005) Structure of the apoptotic protease-activating factor 1 bound to ADP. Nature 434: 926-933

24. Seiffert BM, Vier J and Hacker G (2002) Subcellular localization, oligomerization, and ATP-binding of Caenorhabditis elegans CED-4. Biochem. Biophys. Res. Commun. 290: 359-365

25. Vediyappan G, Bikandi J, Braley R and Chaffin WL (2000) Cell surface proteins of Candida albicans: preparation of extracts and improved detection of proteins. Electrophoresis 21: 956-961

26. Perugini MA, Schuck $P$ and Howlett GJ (2000) Self-association of human apolipoprotein E3 and E4 in the presence and absence of phospholipid. J. Biol. Chem. 275: 36758-36765

27. Schumacher B, Schertel C, Wittenburg N, Tuck S, Mitani S, Gartner A, Conradt $B$ and Shaham S (2005) C. elegans ced-13 can promote apoptosis and is induced in response to DNA damage. Cell Death Differ. 12: 153-161

28. Vaux DL, Weissman IL and Kim SK (1992) Prevention of programmed cell death in Caenorhabditis elegans by human bcl-2. Science 258: 1955-1957

29. Kim KJ, Kim HE, Lee KH, Han W, Yi MJ, Jeong J and Oh BH (2004) Twopromoter vector is highly efficient for overproduction of protein complexes. Protein Sci. 13: 1698-1703

30. Chen L, Willis SN, Wei A, Smith BJ, Fletcher JI, Hinds MG, Colman PM, Day CL, Adams JM and Huang DC (2005) Differential targeting of prosurvival Bcl-2 proteins by their $\mathrm{BH} 3-0 n l y$ ligands allows complementary apoptotic function. Mol. Cell 17: 393-403

31. Chaudhary D, O'Rourke K, Chinnaiyan AM and Dixit VM (1998) The death inhibitory molecules CED-9 and CED-4L use a common mechanism to inhibit the CED-3 death protease. J. Biol. Chem. 273: 17708-17712

32. Chao Y, Shiozaki EN, Srinivasula SM, Rigotti DJ, Fairman R and Shi Y (2005) Engineering a dimeric caspase-9: a re-evaluation of the induced proximity model for caspase activation. PloS. Biol. 3: e183

33. Kunkel TA, Bebenek K and McClary J (1991) Efficient site-directed mutagenesis using uracil-containing DNA. Methods Enzymol. 204: 125-139

34. Laue TM, Shah BD, Ridgeway TM and Pelletier SL (1992) Computer aided interpretation of analytical sedimentation data for proteins. In Analytical Ultracentrifugation in Biochemistry and Polymer Science Harding SE, Rowe AJ and Horton JC (eds) (Cambridge: The Royal Society of Chemistry) pp. 90-125

35. Schuck P (2000) Size-distribution analysis of macromolecules by sedimentation velocity ultracentrifugation and lamm equation modeling. Biophys. J. 78: 1606-1619

36. Vistica J, Dam J, Balbo A, Yikilmaz E, Mariuzza RA, Rouault TA and Schuck P (2004) Sedimentation equilibrium analysis of protein interactions with global implicit mass conservation constraints and systematic noise decomposition. Anal. Biochem. 326: 234-256

37. Wilson-Annan J, O'Reilly LA, Crawford SA, Hausmann G, Beaumont JG, Parma LP, Chen L, Lackmann M, Lithgow T, Hinds MG, Day CL, Adams JM and Huang DC (2003) Proapoptotic BH3-only proteins trigger membrane integration of prosurvival Bcl-w and neutralize its activity. J. Cell Biol. 162: $877-887$

Supplementary Information accompanies the paper on Cell Death and Diffrentiation website (http://www.nature.com/cdd). 